\title{
DESEMPENHO DO CATALISADOR KF-SiO2 NA SÍNTESE DE BIODIESEL ${ }^{1}$
}

\author{
Carolline Rodrigues Ranucci², Helton José Alves ${ }^{3}$, Cristie Luis Kugelmeier ${ }^{4}$, Kenia Gabriela dos Santos ${ }^{5}$
}

${ }^{1}$ Aceito para publicação, $2^{\circ}$ trimestre de 2013.

2 Mestranda em Bioenergia, pela Universidade Estadual do Oeste do Paraná (Unioeste)- Toledo-Paraná, Brasil. Tecnóloga em Biocombustíveis pela Universidade Federal do Paraná - Setor Palotina - Paraná, Brasil.

${ }^{3}$ Químico, Doutor, Docente do curso de Tecnologia em Biocombustíveis, UFPR-Setor Palotina-Paraná, Brasil.

${ }^{4}$ Acadêmico do Curso Superior de Tecnologia em Biocombustíveis, UFPR - Setor Palotina - PR, Brasil.

${ }^{5}$ Acadêmica do Curso Superior de Tecnologia em Biocombustíveis, UFPR - Setor Palotina - PR, Brasil;

Palavras-chave: Biodiesel, catálise heterogênea, MCM-41, fluoreto de potássio.

\section{Resumo}

A procura por fontes renováveis de energia vem aumentando a cada ano, e neste cenário o biodiesel vem recebendo crescente atenção. O biodiesel pode ser produzido pela reação de transesterificação ou alcoólise, sendo que neste processo óleos vegetais e/ou gorduras reagem com um álcool de cadeia curta, geralmente metanol ou etanol. As reações ocorrem na presença de um catalisador, seja este ácido, básico ou enzimático, podendo ser homogêneo ou heterogêneo. Tradicionalmente é obtido pela transesterificação na presença de um catalisador homogêneo alcalino, frequentemente $\mathrm{NaOH}$ ou $\mathrm{KOH}$, sendo estes não recuperáveis e passíveis de formação de subprodutos indesejáveis (sabão), contribuindo para a elevação de custos e geração de resíduos. O propósito deste trabalho foi produzir ésteres metílicos a partir do óleo de soja por uma rota alternativa, utilizando um catalisador heterogêneo, devido às vantagens conferidas ao processo produtivo, como facilidade na separação do biodiesel do meio reacional, ausência de reações paralelas e possibilidade de reuso do catalisador em novas reações. Dentre os inúmeros catalisadores heterogêneos, foi sintetizada a peneira molecular mesoporosa MCM-41 a base de sílica de acordo com o método descrito por Grün. Após a síntese das peneiras foi realizado o tratamento com um sal inorgânico, o fluoreto de potássio (KF), a fim de se obter catalisadores mais estáveis. Os materiais sólidos preparados foram caracterizados por diferentes técnicas, como a 
Microscopia Eletrônica de Varredura (MEV), Difratometria de Raios-X (DRX) e Análise Termogravimétrica (ATG). Já os ésteres metílicos foram analisados por Ressonância Magnética Nuclear de Hidrogênio (RMN 1H). Os resultados indicaram que o material foi sintetizado corretamente e a taxa de conversão em ésteres metílicos foi elevada $(94,8 \%)$, além disso, apresentaram maior estabilidade, tornando-se promissores catalisadores heterogêneos para a utilização em reações de transesterificação.

\section{Introdução}

Atender a demanda energética mundial tem sido um grande desafio para a sociedade. A elevação contínua do preço do barril de petróleo, as preocupações com a diminuição gradativa das reservas e as questões ambientais associadas à queima de combustíveis fósseis também têm contribuído para que surjam cada vez mais iniciativas para potencializar o uso de fontes alternativas de energia [1].

Dentre os biocombustíveis, o biodiesel vem recebendo atenção crescente por ser considerado um substituto parcial ou integral ao diesel de petróleo, ou seja, por se tratar de um biocombustível que possui grande adaptabilidade em motores de combustão interna (motores do ciclo diesel) [2].

O biodiesel constitui-se de metil ésteres de ácidos graxos (FAME) ou etil ésteres de ácidos graxos (FAEE), obtidos da transesterificação de triglicerídeos de óleos e gorduras com álcoois de cadeia curta como metanol ou etanol, respectivamente na presença de um determinado catalisador $[1,3]$.

A produção de biodiesel em nosso país está aumentando gradativamente, em virtude disso, a tecnologia também deve acompanhar essa perspectiva. Um aspecto de grande importância é a catálise e um fator que merece atenção especial é a análise dos catalisadores utilizados, sejam eles homogêneos ou heterogêneos [4].

Atualmente, o maior volume de biodiesel produzido é obtido através da transesterificação via catálise alcalina em meio homogêneo, utilizando como catalisadores hidróxidos de sódio $(\mathrm{NaOH})$ ou potássio $(\mathrm{KOH})$ ou seus alcóxidos correspondentes. Este processo é mais econômico porque os catalisadores são de baixo custo [2,5,6].

Entretanto, os catalisadores alcalinos homogêneos podem absorver água com facilidade, durante o armazenamento. A presença de água e ácidos graxos livres interfere fortemente no equilíbrio da reação, pois, podem levar a formação de sabões, uma reação secundária e indesejável, que além de consumir parte do catalisador, diminui o rendimento 
das reações, dificulta a separação dos ésteres e glicerina, sendo necessária a realização de várias etapas de separação e purificação dos produtos $[1,2,5,6]$.

Com o objetivo de minimizar os problemas relacionados ao processo homogêneo, sistemas envolvendo catálise heterogênea têm sido amplamente investigados pela comunidade científica nos últimos anos $[1,2]$.

O emprego de catalisadores heterogêneos apresenta algumas vantagens, dentre as quais pode-se mencionar: i) facilidade de separação e purificação do biocombustível do meio reacional; ii) recuperação do catalisador por filtração ou centrifugação; iii) recuperação do excesso de álcool por destilação e separação da glicerina do biocombustível por decantação; iv) ausência de reações paralelas como a de saponificação; e v) possibilidade de reutilização do catalisador em novas reações $[1,2,7,8]$.

Objeto de estudo a mais de quinze anos, as peneiras moleculares da família M41S (MCM-41, MCM-48 e MCM-50) são exemplos de catalisadores heterogêneos. Descoberta por pesquisadores da Mobil na década de 90. Esses materiais apresentam uma grande utilidade como catalisadores e adsorventes devido à sua grande superfície interna $[9,10]$.

Estas podem ser preparadas por diversos métodos descritos na literatura [11,12], que de uma maneira geral, resultam da combinação de quarto componentes: 1) direcionador de estrutura (surfactante); 2) agente mineralizante; 3) fonte de sílica; 4) solvente [11-13]. É possível manipular as propriedades destes materiais, por exemplo, variando o tamanho da cadeia do agente direcionador ou alterando a razão molar (RM) utilizada entre os componentes, dentre outras variáveis possíveis $[13,14]$.

Segundo Beck e colaboradores [10], a diferença entre esses materiais da mesma família é determinada pela relação surfactante/silício (surf/Si), onde: a) surf/Si < 1: formação da fase hexagonal MCM-41; b) $1<\operatorname{surf} / \mathrm{Si}<2$ : na composição inferior do intervalo forma-se a fase cúbica MCM-48 e na superior a fase lamelar MCM-50; c) surf/Si > 2: devido ao excesso de surfactante há a formação de seu octâmero cúbico (silicato de cetiltrimetilamônio $\left[\left(\text { surf) } \mathrm{SiO}_{2,5}\right]_{8}\right)$ (Figura 1).
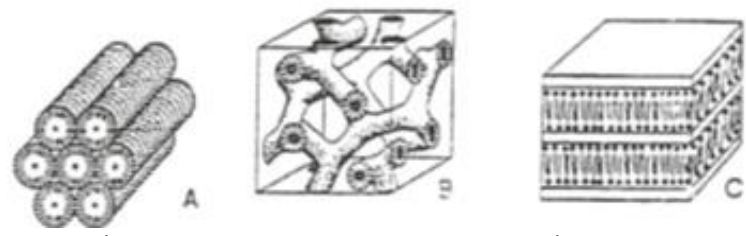

Figura1. Representação esquemática das estruturas de cristal líquido, (A) MCM-41, (B) MCM-48 e (C) MCM-50. 
Dentre os membros da família M41S, a peneira mais estudada é a MCM-41, que se destaca por possuir sistema regular de poros cilíndricos regularmente espaçados (diâmetros entre 2 e $10 \mathrm{~nm}$ ), elevada área superficial (até $1400 \mathrm{~m}^{2} / \mathrm{g}$ ) e estabilidade térmica [12,15].

Por possuir sítios ativos básicos, atribuídos à fraca interação dos cátions do surfactante $\left(\mathrm{CTA}^{+} /\right.$cetiltrimetilamônio) com os ânions silóxi ( $\mathrm{SiO}^{-} /$rede de sílica), a peneira molecular $\left[\mathrm{CTA}^{+}\right] \mathrm{Si}-\mathrm{MCM}-41$ possui propriedades catalíticas promissoras em reações orgânicas, dentre as quais merece destaque a reação de transesterificação de óleos vegetais para a produção de monoésteresalquílicos (biodiesel)

Contudo a aplicação de catalisadores heterogêneos apresenta algumas limitações, como por exemplo: I) apresentam menor atividade que os homogêneos em geral, necessitam de condições experimentais mais severas como alta temperatura e pressão, ou tempos de reações maiores para alcançar valores de conversão similares aos obtidos no processo homogêneo [16]; II) elevado custo em sua síntese e III) baixa estabilidade no reuso, alguns podem perder sua atividade catalítica pelo processo de lixiviação, o que pode também resultar em uma parcela de contribuição homogênea à reação de transesterificação e contaminação dos ésteres e glicerina formados [17], entre outras limitações.

A peneira molecular mesoporosa MCM-41 apesar de apresentar elevada atividade catalítica pode sofrer perda parcial de sua massa. O problema da peneira recém sintetizada é devido à lixiviação dos cátions $\mathrm{CTA}^{+}$. Este fato pode fazer com que o material reduza lentamente sua atividade e que a catálise ocorra tanto na forma heterogênea quanto homogênea [18].

Perante o problema de lixiviação da espécie catalítica, estudos têm sido descritos na literatura com o objetivo de investigar meios de se evitar as perdas mássicas a partir da imobilização dos catalisadores em suportes inertes.Neste contexto, as peneiras moleculares mesoporosas (calcinadas) do tipo MCM-41 apresentam-se como promissores suportes catalíticos para o desenvolvimento de novos catalisadores heterogêneos, com fases ativas e bem dispersas [2].

Neste trabalho foi realizada a incorporação de um sal inorgânico, o fluoreto de potássio, com o intuito de substituir o $\mathrm{CTA}^{+}$que apresenta um elevado custo e é de fácil lixiviação, desenvolvendo um novo catalisador básico com maior estabilidade na reação de transesterificação.

Durante o processo de impregnação pode ocorrer um ataque dos íons fluoreto ao silício presente na estrutura do material, resultando na formação de ligações $\mathrm{Si}-\mathrm{F}[19]$, isso 
ocorre devido à similaridade dos raios atômicos, onde o íon flúor $\left(\mathrm{r}_{\mathrm{F}-}=1,33 \bigoplus\right)$ pode substituir o íon oxigênio $\left(\mathrm{r}_{\mathrm{O}_{2}}=1,32 \bigoplus\right)$, provocando quebra de ligações devido à sua monovalência [20]:

$$
\equiv \mathrm{Si}-\mathrm{O}-\mathrm{Si} \equiv+\mathrm{F}^{-} \rightarrow \equiv \mathrm{Si}-\mathrm{F}+{ }^{-} \mathrm{O}-\mathrm{Si} \equiv
$$

Os sítios ativos básicos quando gerados, correspondem aos oxigênios (com carga negativa) localizados nas proximidades dos íons fluoreto, sendo que a presença dos cátions $\mathrm{K}^{+}$ distribuídos ao redor dos sítios ativos é determinante para gerar a basicidade do catalisador [21].

\section{Materiais e Métodos}

\subsection{Síntese dos catalisadores}

A peneira molecular [CTA+]Si-MCM-41 foi sintetizada utilizando o método descrito por Grünet al. [13]. Este método proporciona uma excelente reprodutibilidade, ocorre em temperatura ambiente e em menor tempo. O meio reacional foi composto por $\mathrm{CTMABr}-$ 99\% Sigma (agente direcionador), $\mathrm{NH} 4 \mathrm{OH}$ - 29\% Fmaia (agente mineralizante), TEOS 98\% AcrosOrganics (tetraetilortosilicato) como fonte de sílica, EtOH absoluto - 95\% (álcool etílico) como co-solvente do TEOS e água ultra-purificada.Inicialmente, o brometo de cetiltrimetilamônio (CTABr) foi dissolvido em água deionizada, sendo em seguida adicionados hidróxido de amônio ( $\mathrm{NH} 4 \mathrm{OH})$ e etanol absoluto (co-solvente). A solução foi agitada por $15 \min$ a $30^{\circ} \mathrm{C}$. Na sequência, foi adicionado tetraetilortosilicato (TEOS). A mistura permaneceu sob agitação por $2 \mathrm{~h}$, sendo em seguida filtrada e o precipitado obtido lavado com água deionizada. $\mathrm{O}$ material resultante foi seco em estufa a $60^{\circ} \mathrm{C}$ por $24 \mathrm{~h}$.

\subsubsection{Impregnação de fluoreto de potássio}

Após a secagem, a amostra foi desagregada e calcinada para a remoção do material orgânico (surfactante) que estava ocluído nos mesoporos. A calcinação foi realizada em uma mufla, com a seguinte rampa de aquecimento: i) aquecimento de $3^{\circ} \mathrm{C} / \mathrm{min}$ até atingir $200{ }^{\circ} \mathrm{C}$, permanecendo nesta temperatura por 30 minutos; ii) aquecimento de $3{ }^{\circ} \mathrm{C} / \mathrm{min}$ até $280{ }^{\circ} \mathrm{C}$, mantendo a temperatura por 60 minutos e iii) aquecimento de $3{ }^{\circ} \mathrm{C} / \mathrm{min}$ até $520{ }^{\circ} \mathrm{C}$ permanecendo nesta temperatura por 240 minutos. Na sequência, a amostra foi submetida ao tratamento com o sal inorgânico (KF - 98\% Synth). Inicialmente preparou-se uma suspensão 
de $15 \%(\mathrm{~m} / \mathrm{v})$ da peneira calcinada em solução de KF $1,5 \mathrm{~mol} / \mathrm{L}$, a qual foi mantida sob agitação constante em um sistema de refluxo a $80{ }^{\circ} \mathrm{C}$ por 30 minutos. Em seguida, a suspensão foi levada para uma chapa de aquecimento com agitação para a remoção da água, sendo então submetida a secagem completa em estufa elétrica a $110{ }^{\circ} \mathrm{C}$ durante 24 horas. Posteriormente ocorreu a desaglomeração dos catalisadores obtidos.

\subsubsection{Caracterização dos catalisadores}

A seguir, serão descritos os métodos de caracterização utilizados para o conhecimento dos materiais.

I) Difratometria de raios $\mathbf{X}$ (DRX): A técnica de difração de raios $X$ foi empregada com o intuito de determinar as fases cristalinas do material sólido e de sua cristalinidade (grau de organização dos cristalitos). O estudo de Difração de raios X (DRX) foi realizado utilizando um DifratômetroRigakuGeingerflex (radiação de $\mathrm{Cu} \mathrm{K \alpha} 45 \mathrm{kV}-25 \mathrm{~mA}$ ) com varredura de 1,5 $<2 \Theta<40^{\circ}$ com velocidade de $1 \%$ minuto.

III) Microscopia Eletrônica de Varredura (MEV): A técnica de microscopia eletrônica de varredura possibilita o estudo da morfologia, distribuição das partículas e o tamanho das partículas dos materiais. Ao MEV pode ser acoplado o sistema de EDS, este possibilita a determinação da composição qualitativa e semiquantitativa das amostras.

Foi utilizado um microscópio eletrônico de varredura, FEI Quanta 440, com sistema de EDS acoplado.As amostras foram suspensas em metanol e depositadas sob um porta amostra, sendo posteriormente secas e metalizadas com uma fina camada de ouro na superfície.

IV) Análise termogravimétrica (ATG): A análise termogravimétrica é uma das técnicas de análise térmica em que a perda de massa da amostra é monitorada como uma função da temperatura. A utilização da ATG, além da estabilidade térmica, permite avaliar a quantidade de água fisissorvida nas amostras e a decomposição térmica dos cátions orgânicos (quando os surfactantes são usados na síntese das peneiras moleculares).

As amostras foram analisadas em um equipamento TA Instruments Q-500 com programa controlado de temperatura, variando da temperatura ambiente a $800{ }^{\circ} \mathrm{C}$ com fluxo de nitrogênio de 40,0 $\mathrm{mL} /$ minuto e taxa de aquecimento de $10{ }^{\circ} \mathrm{C} /$ minuto.

\subsection{Teste catalítico - Transesterificação}


O desempenho catalítico dos catalisadores foi avaliado na transesterificação do óleo de soja comercial, na presença de metanol anidro, sob as seguintes condições: RM metanol/óleo de $12: 1$, temperatura de $70^{\circ} \mathrm{C}$, tempo de reação de 1 hora e $5 \% \mathrm{~m} / \mathrm{m}$ de catalisador. A reação foi conduzida sob agitação magnética em um reator de aço inox equipado com um manômetro.

Ao final do tempo reacional o catalisador foi separado por filtração a vácuo e a fase orgânica submetida à centrifugação. A fase biodiesel foi levada para um evaporador rotatório a vácuo para a retirada do excesso de metanol, sendo em seguida avaliada por espectroscopia de ressonância magnética nuclear de hidrogênio (1H RMN - Bruker Avance III, 9,4T, 400 MHz). Com base na análise quantitativa dos ésteres metílicos o percentual de conversão do óleo de soja em biodiesel foi determinado [22].

O cálculo de conversão foi feito de acordo com a equação (Equação 1) descrita por Knothe[22] onde calcula-se a integral dos picos referentes aos prótons dos glicerídeos e dos ésteres metílicos formados.

\section{$\mathrm{C}_{\mathrm{ME}}=100^{*} \frac{5^{*} \mathrm{I}_{\mathrm{ME}}}{5 * \mathrm{I}_{\mathrm{ME}}+9 * \mathrm{I}_{\mathrm{TAG}}}$}

Equação (1)

Onde: $\mathrm{C}_{\mathrm{ME}}$ é a concentração de ésteres metílicos, $\mathrm{I}_{\mathrm{ME}}$ é a integral da área do pico do metil éster e $\mathrm{I}_{\mathrm{TAG}}$ é a integral do valor do pico dos glicerídeos do triacilglicerol do óleo vegetal.

\subsubsection{Ensaio de lixiviação dos catalisadores}

Realizou-se ensaio para verificar se houve lixiviação do catalisador utilizado e assim estimar a contribuição homogênea do catalisador na reação. Neste ensaio, primeiramente pesou-se 1,39 $\mathrm{g}$ de cada catalisador os quais foram colocados em um papel filtro quantitativo (fechado com "clips" formando pequenos envelopes). Posteriormente as amostras foram mantidas por 10 horas em sistema de refluxo, em soxhlet, em contato com $150 \mathrm{~mL}$ de metanol. Ao término do refluxo, as amostras foram secas em estufa elétrica a $100{ }^{\circ} \mathrm{C}$ por 48 horas. Após esse período, pesou-se novamente as amostras para a avaliação da perda mássica dos catalisadores. O metanol foi recuperado e utilizado em uma nova reação com o óleo de soja, sem a adição do catalisador. A presença de espécies lixiviadas pode ser determinada pela taxa de conversão nesta segunda reação. 


\section{Conclusões}

A seguir serão apresentados os resultados obtidos na síntese, caracterização e avaliação catalítica dos catalisadores.

\subsection{Síntese e caracterização dos catalisadores}

\subsubsection{Difratometria de Raios X (DRX)}

Na Figura 2 observa-se os difratogramas de raios X da amostra MCM-41 antes e após a calcinação, além da amostra submetida a impregnação com o sal antes e após o ensaio de lixiviação.Nota-se que no espectro da MCM-41 não calcinada e da amostra calcinada (Figura 2), ocorreu um deslocamento do pico principal (100) para ângulos $2 \theta$ menores. Este deslocamento pode ser relacionado com o arranjo desordenado dos poros, resultando em um aumento da distância interplanar reduzindo o valor de $2 \theta$.

O código da amostra submetida ao tratamento com o sal inorgânico (KF) foi modificado, em virtude que, este não apresenta no difratograma os picos característicos da peneira molecular mesoporosa MCM-41, sendo apenas um material constituído a base de sílica, passando a denominar-se $\mathrm{KF}-\mathrm{SiO}_{2}$ - B.

No difratograma da amostra modificada (Figura 2), os picos presentes em 21, 22, 24, 28,31 e $37^{\circ}(2 \theta)$ são referentes a fase $\mathrm{KHSi}_{2} \mathrm{O}_{5}$, presente na forma de traços. Já na mesma amostra quando submetida ao ensaio de lixiviação (refluxo) observa-se a presença da fase $\mathrm{K}_{2} \mathrm{SiF}_{6}$ com os picos correspondentes indexados em $18,32,38$ e $45^{\circ}(2 \theta)$. Já os picos em 33 e $42^{\circ}(2 \theta)$ são típicos de $\mathrm{KH}_{3} \mathrm{~F}_{4}$, sendo encontrados apenas traços dessa fase. A fase com maior predominância no catalisador lixiviado é a $\mathrm{KHSi}_{2} \mathrm{O}_{5} \mathrm{com}$ vários picos característicos em 21, $22,24,28,31$ e $37^{\circ}(2 \theta)$. Estes picos sugerem que ocorreu a incorporação do sal na estrutura da peneira molecular a base de sílica.

Quando a amostra foi submetida ao refluxo, observa-se que os picos se tornaram mais intensos fato que pode ser relacionado com uma maior evidencia das outras fases, visto que o pico principal se tornou menos intenso. 


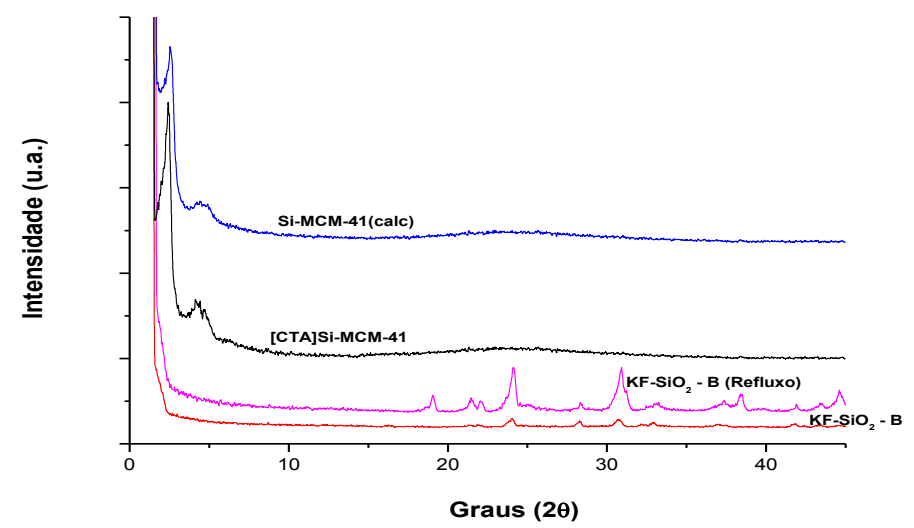

Figura2. Difratogramas das amostras Si-MCM-41 antes e após a calcinação e da KF-SiO - B.

\subsubsection{Microscopia Eletrônica de Varredura}

Para as amostras sintetizadas pelo método descrito por Grün, calcinadas e não calcinadas, foram obtidas partículas esféricas, com distribuição homogênea e com diâmetro médio abaixo de $1 \mu \mathrm{m}$, típicas da Si-MCM-41 (Figura 4 (a) e (b)).

$\mathrm{Na}$ Figura 4(d) são observadas partículas com morfologia irregular, apresentando algumas com o formato de prisma com tamanho médio abaixo de $1,5 \mu \mathrm{m}$.

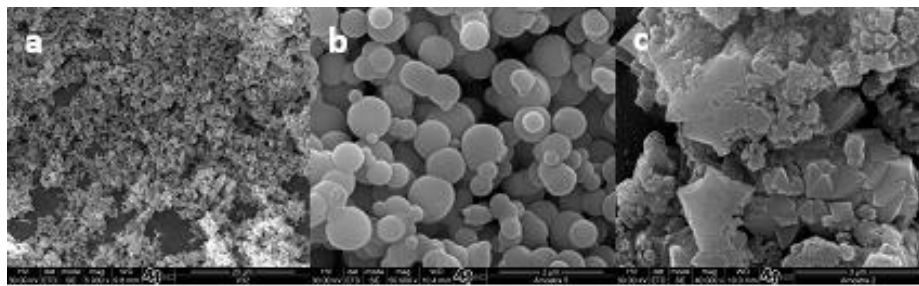

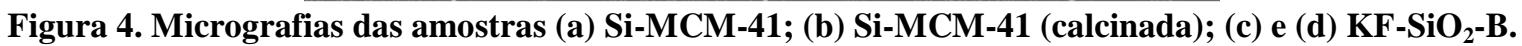
Aumentos (a); (b) 50.000X e (c) 40.000X.

A amostra modificada após ser submetida ao ensaio de lixiviação pode ser visualizada na Figura 5 (a), verificando a existência de partículas com morfologia irregular e distribuição heterogênea. Na Figura 5 (b) observa-se o detalhe de regiões "ocas" no interior das partículas com formato hexagonal, evidenciadas pelo ataque do sal a estrutura da peneira.

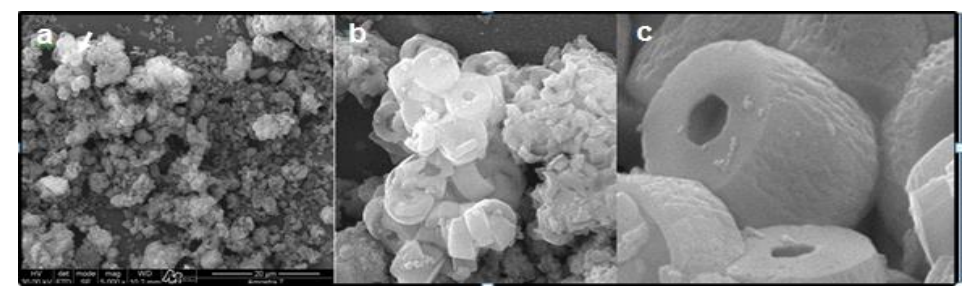

Figura5. Micrografias da amostra $\mathrm{KF}_{-} \mathrm{SiO}_{2}-\mathrm{B}$ após o ensaio de lixiviação. (a) Aumento de 5.000X; (b) e (c) Detalhe das regiões "ocas" no interior das partículas. 
Realizou-se também a análise semi-quantitativa das amostras (EDS). Na Tabela 1 observa-se o percentual de todos os elementos encontrados no material sólido.

Tabela1. Análise semi-quantitativa (EDS) das amostras.

\begin{tabular}{|c|c|c|c|c|c|c|c|c|c|}
\hline \multirow{2}{*}{ Amostra } & \multicolumn{9}{|c|}{$\%$ em massa } \\
\hline & $\mathbf{C}$ & $\mathbf{O}$ & $\mathbf{F}$ & $\mathbf{N a}$ & Al & Si & $\mathbf{S}$ & $\mathbf{K}$ & Total \\
\hline Si-MCM-41 & 10,50 & 53,79 & - & 0,01 & 0,25 & 35,38 & 0,07 & - & 100 \\
\hline $\begin{array}{l}\text { Si-MCM-41 } \\
\text { (Calcinada) }\end{array}$ & 3,36 & 58,55 & - & 0,07 & 0,52 & 39,00 & - & - & 100 \\
\hline $\mathrm{KF}-\mathrm{SiO}_{2}-\mathrm{B}$ & 7,81 & 22,46 & 25,47 & 0,11 & 0,20 & 7,63 & 0,02 & 36,31 & 100 \\
\hline $\begin{array}{c}\text { KF-SiO2 - B } \\
\text { (Refluxo) }\end{array}$ & 1,81 & 31,06 & 24,33 & 0,07 & 0,14 & 20,47 & - & 22,13 & 100 \\
\hline
\end{tabular}

Nota-se que a quantidade de flúor (F) na amostra permanece semelhante mesmo após ser submetido ao refluxo. Já o percentual de potássio (K) decresceu significamente após as 10 horas de refluxo $(14,18 \%)$, indicando que ocorreu perda parcial do sólido no meio reacional por lixiviação.

\subsubsection{Análise Termogravimétrica (ATG)}

A análise termogravimétrica dos materiais foi realizada para quantificar a perda de massa.NaFigura 6 , constata-se a presença de três regiões referentes à perda de massa. A primeira região está relacionada à perda de água adsorvida (abaixo de $150^{\circ} \mathrm{C}$ ).

A segunda região, entre 150 e aproximadamente $318{ }^{\circ} \mathrm{C}$ está relacionada à decomposição do cátion $\mathrm{CTA}^{+}$. Após a saída do surfactante observa-se que o material continua perdendo massa de forma constante, devido à perda de água pela condensação dos grupos silanóis da superfície interna dos poros, que interagiam com as moléculas do direcionador, esta região encontra-se na faixa acima de $400{ }^{\circ} \mathrm{C}$ [23].

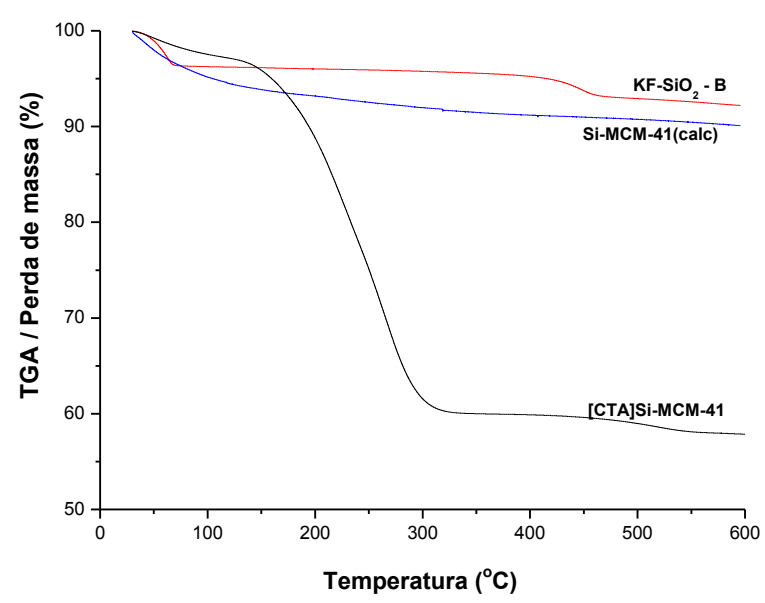

Figura6. Curvas ATG da perda de massa das amostras Si-MCM-41 calcinada e não calcinada e da amostra $\mathrm{KF}-\mathrm{SiO}_{2}$ - B em função da temperatura. 
Para uma melhor visualização da perda de massa e a porcentagem de sólido restante, os valores foram retratados na Tabela 2. Na peneira mesoporosa tradicional, a maior perda de massa é observada entre $150-225{ }^{\circ} \mathrm{C}$ e na regiãoentre $225-300^{\circ} \mathrm{C}$,sendo estaúltima relacionada com a decomposição do surfactante. Já na amostra impregnada com o sal inorgânico a perda de massa maior foi visualizada entre 400 e $500^{\circ} \mathrm{C}$.

Tabela 2. Perda de massa relacionada com a elevação da temperatura e porcentagem de massa perdida

\begin{tabular}{|c|c|c|c|c|c|c|}
\hline \multirow[b]{2}{*}{$\begin{array}{c}\text { Temperatura } \\
\left({ }^{\circ} \mathrm{C}\right)\end{array}$} & \multicolumn{2}{|c|}{ [CTA]Si-MCM-41 } & \multicolumn{2}{|c|}{$\begin{array}{l}\text { Si-MCM-41 } \\
\text { (Calcinada) }\end{array}$} & \multicolumn{2}{|c|}{$\mathrm{KF}-\mathrm{SiO}_{2}-\mathrm{B}$} \\
\hline & $\begin{array}{c}\text { Massa } \\
(\mathrm{mg})\end{array}$ & $\begin{array}{c}\text { Perda de } \\
\text { massa } \\
(\%)\end{array}$ & $\begin{array}{c}\text { Massa } \\
(\mathrm{mg})\end{array}$ & $\begin{array}{c}\text { Perda de } \\
\text { massa } \\
(\%)\end{array}$ & $\begin{array}{c}\text { Massa } \\
(\mathrm{mg})\end{array}$ & $\begin{array}{c}\text { Perda de } \\
\text { massa } \\
(\%)\end{array}$ \\
\hline 30 & 9,21 & 0 & 3,21 & 0 & 21,07 & 0 \\
\hline 100 & 9,00 & 2,3 & 3,06 & 4,83 & 20,28 & 3,74 \\
\hline 200 & 8,21 & 10,9 & 2,99 & 6,81 & 20,23 & 3,98 \\
\hline 300 & 5,54 & 39,85 & 2,96 & 8,02 & 20,18 & 4,23 \\
\hline 400 & 5,46 & 40,72 & 2,93 & 8,81 & 20,07 & 4,76 \\
\hline 500 & 5,40 & 41,37 & 2,92 & 9,25 & 19,58 & 7,08 \\
\hline 595 & 5,35 & 41,9 & 2,90 & 9,91 & 19,42 & 7,83 \\
\hline
\end{tabular}

A amostra calcinada e a amostra submetida ao tratamento com o sal apresentaram uma menor perda de massa. Este fato pode estar relacionado com o processo de calcinação realizado em ambas as amostras para a remoção do surfactante.

A partir dos dados acima podemos afirmar que a amostra quando submetida ao tratamento com o sal KF apresentou uma maior estabilidade frente as demais amostras.

\subsection{Ensaio de Lixiviação}

Com o propósito de verificar a perda mássica dos catalisadores no meio reacional, foi realizado o ensaio de lixiviação. Com a perda parcial das amostras durante as reações pode ocorrer a contribuição homogênea além de levar a uma diminuição da atividade catalítica quando aplicados na transesterificação.Os resultados obtidos no ensaio de lixiviação estão descritos na Tabela 3.

Tabela3. Perda mássica dos catalisadores no ensaio de lixiviação.

\begin{tabular}{cccc}
\hline Amostra & Massa inicial (g) & Massa final (g) & \% Perda \\
\hline Si-MCM-41 & 1,3931 & 0,9645 & 30,7 \\
KF-SiO $_{2}$ - B & 2,7681 & 2,2515 & 18,62 \\
\hline
\end{tabular}


$\mathrm{O}$ catalisador $\mathrm{KF}-\mathrm{SiO}_{2}-\mathrm{B}$ apresenta uma basicidade menos lixiviável quando comparada a peneira molecular MCM-41. Este fato pode ser de extrema importância na escolha deste tipo de catalisador na reação de transesterificação, fazendo com que esta fração contenha menor quantidade de resquícios de catalisador.

\subsection{Síntese de ésteres metílicos}

A atividade catalítica dos sólidos sintetizados neste trabalho foram avaliadas perante a aplicação dos mesmos na reação de transesterificação para a obtenção de ésteres metílicos a partir do óleo de soja. As amostras foram analisadas por ressonância magnética nuclear de hidrogênio.

Na Figura 7 são observados os espectros de RMN1H dos materiais sintetizados neste trabalho.

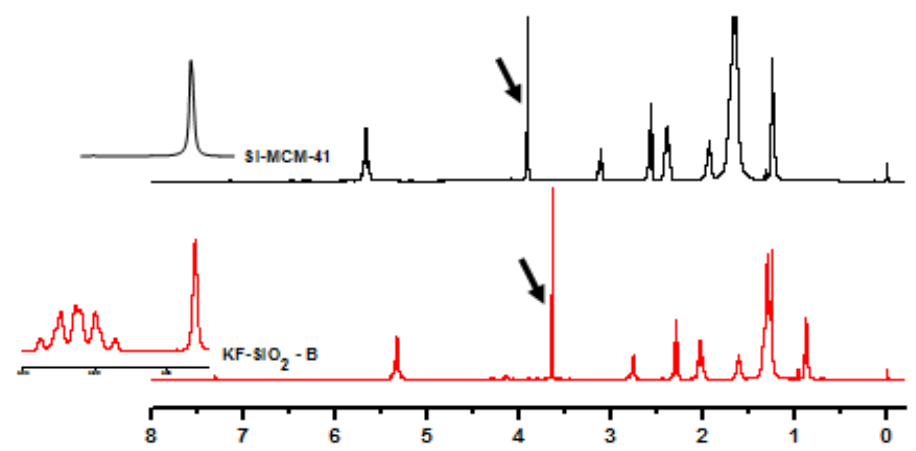

Figura 72.RMN ${ }^{1} \mathrm{H}$ das amostras de ésteres metílicos. Detalhe dos picos referentes aos ésteres metílicos e dos triglicerídeos.

A taxa de conversão dos triglicerídeos do óleo de soja em ésteres metílicos está relacionada com a intensidade do pico observado em aproximadamente 3,9 ppm, referente ao éster metílico. Quanto maior este pico, maior será a taxa de conversão em biodiesel.

Na Tabela 4 estão apresentados os valores de conversão em ésteres metílicos, baseados na equação (Equação 1) descrita por Knothe [22].

Tabela4. Taxa de conversão em ésteres metílicos.

\begin{tabular}{cccc}
\hline Amostra & Óleo/Álcool & $\begin{array}{c}\text { \% Catalisador } \\
(\mathbf{m} / \mathbf{m})\end{array}$ & $\begin{array}{c}\text { \% de conversão em } \\
\text { biodiesel }\end{array}$ \\
\hline $\mathrm{Si}-\mathrm{MCM}-41$ & $1: 12$ & $5 \%$ & 92,89 \\
$\mathrm{KF}_{\mathrm{SiO}}-\mathrm{B}$ & $1: 12$ & $5 \%$ & 94,8 \\
\hline
\end{tabular}


A peneira calcinada foi aplicada na reação para a obtenção de ésteres metílicos, contudo não ocorreu a separação de fases entre o éster e a glicerina não sendo possível caracterizar e quantificar o produto principal.

Realizou-se também uma reação de transesterificação com o metanol recuperado do sistema de refluxo e óleo de soja, sem a adição de catalisador. Verificou-se nessa segunda reação (Tabela 5) que a peneira molecular MCM-41 apresentou uma taxa de conversão de $4,72 \%$, indício que houve perda parcial do catalisador no meio reacional por lixiviação dos cátions $\mathrm{CTA}^{+}$. Já a amostra tratada com o KF, não ocorreu a conversão em ésteres metílicos comprovando que este tipo de catalisador é mais estável quando comparado a peneira tradicional (MCM-41).

Tabela 5. Taxa de conversão em ésteres metílicos sem a utilização de catalisadores.

\begin{tabular}{cccc}
\hline Amostra & Massa de óleo $(\mathbf{g})$ & $\begin{array}{c}\text { Volume de Metanol } \\
(\mathbf{m L})\end{array}$ & Conversão (\%) \\
\hline Si-MCM-41 & 15 & 9,65 & 4,72 \\
KF-SiO $_{2}-\mathbf{B}$ & 15 & 9,65 & 0 \\
\hline
\end{tabular}




\section{Referências}

1. LÔBO, I. P.; FERREIRA, S. L. C.; CRUZ, R. S. Biodiesel: parâmetros de qualidade e métodos analíticos. Disponível em http://www.scielo.br/scielo.php?pid=S010040422009000600044\&script=sci_arttext. Acesso em 06 de Maio de 2013.

2. SANTOS, V. C. Estudos de catalisadores heterogêneos para obtenção de ésteres metílicos a partir da transesterificação de óleos vegetais. Dissertação de Mestrado. Programa de Pós-Graduação em Química, Universidade Federal do Paraná, 2010.

3. ALBUQUERQUE, M. C. G. Síntese, Caracterização e aplicação de catalisadores heterogêneos para a produção de biocombustíveis. Programa de Pós-Graduação em Química, Universidade Federal do Ceará, 2008.

4. BIODIESEL - Programa Nacional de Produção e Uso de Biodiesel. Disponível em http://www.mme.gov.br/programas/biodiesel/menu/biodiesel/o_biodiesel.html. Acesso em 05 de Maio de 2012.

5. CORDEIRO, C. S.; SILVA, F. R.; WYPYCH, F.; RAMOS, L. P. Catalisadores heterogêneos para a produção de monoésteres graxos (biodiesel). Química Nova, v. 34, n. 3, p. 477-486, 2011.

6. HELWANI, Z.; OTHMAN, M. R.; AZIZ, N.;KIM, J.; FERNANDO, W. J. N.Solid heterogeneous catalysts for transesterification of triglycerides with methanol: a review. Applied Catalysis A: General, v. 363, p. 1-10, 2009.

7. MACARIO, A.; GIORDANO, G.; ONIDA, B.; COCINA, D.; TAGARELLI, A.; GIUFFRÈ, A. M.Biodiesel production process by homogeneous/heterogeneous catalytic system using an acid-base catalyst. Applied Catalysis A: General, v. 378, p. 160-168, 2010.

8. VICENTE, G.; MARTÍNEZ, M.;RACIL, J. Integrated biodiesel production: a comparison of different homogeneous catalyst systems. Bioresource Technology, v.92, p. 297-305, 2004.

9. FUKUDA, H.; KONDO, A.; NODA, H. Biodiesel fuel productionbytrasesterification of oils. Journal of Bioscience and Bioengineering, v. 92, p. 405-416, 2001.

10. KRESGE, C.T.; VARTULI, J. C.; ROTH, W. J.; LEONOWICZ, M. E. The discovery of ExxonMobil's M41S family of mesoporousmolecularsieves.Studies in SurfaceScience and Catalysis, v. 148, p. 53-72, 2004.

11. BECK, J.S.; VARTULI, J. C.; ROTH, W. J.; LEONOWICZ, M. E.; KRESGE, C. T.; SCHMITT, K. D.; CHU, C. T. W.; OLSON, D. H.; SHEPPARD, E. W. A new family of mesoporous molecular sieves with liquid crystaltemplates.J. Am. Chem. Soc., v. 114, p. 10834-10843, 1992.

12. CHENG, C. F., PARK, D. H., e KLINOWSKI, J. J. Chem. Soc., Faraday Trans. 93, 193 (1997).

13. GRÜN, M.; UNGER, K. K.; MATSUMOTO, A.; TSUTSUMI, K.Novel pathways for the preparation of mesoporous MCM-41 materials: controlo f porosity and morphology. MicroporousandMesoporousMaterials, v. 27, p. 207-216, 1999.

14. MARTINS, L.; CARDOSO, D. Influence of surfactant chain length on basic catalytic properties of Si-MCM-41. Microporous and Mesoporous Materials, v. 106, p. 8-16, 2007.

15. KUBOTA Y.; NISHIZAKI, Y.; IKEVA, H.; SAEKI, M.; HIDA, T.; KAWAZU, S.; YOSHIDA, M.; FUJII, H.; SUGI, Y. Organic-silicate hybrid catalysts based on various defined structures for Knoevenagel condensation. MicroporousandMesoporousMaterials, v. 70, p. 135-149, 2004.

16. DABDOUB, M. J.;BRONZEL, J. L.; RAMPIN, M. A. Biodiesel: visão crítica do status atual e perspectivas na academia e na indústria. Química Nova, vol.32, no.3, p. 776-792, 
São Paulo, 2009. Disponível em http://dx.doi.org/10.1590/S0100-40422009000300021. Acesso em 07 de Março de 2013.

17. DI SERIO, M.; LEDDA, M.; COZZOLINO, M.; MINUTILLO, G.; TESSER, R.; SANTACESARIA, E.Transesterification of soybean oil to biodiesel by using heterogeneous basic catalysts. Ind. Eng. Chem. Res., v. 45, p. 3009-3014, 2006.

18. CRUZ, F. T. Efeito das condições de preparação da [CTA+]-SiMCM-41 na atividade da transesterificação. Programa de Pós-Graduação em Engenharia Química. Universidade Federal de São Carlos, 2010.

19. FABIANO, D.P. Síntese e avaliação de sílica tipo M41S contendo cátions CTA em transesterificação catalítica. Tese de Doutorado. Programa de Pós-Graduação em Engenharia Química da Universidade Federal de São Carlos, São Carlos, 2010.

20. FUJITA, S. I.; BHANAGE, B. M.; AOKI, D.; OCHIAI, Y.; IWASA, N.; ARAI, M. Mesoporoussmectites incorporated with alkali metal cations as solid base catalysts. AppliedCatalysis A: General, v. 313, p. 151-159, 2006.

21. PRADO, U. S.; MARTINELLI, J. R.; BRESSIANI, J. C. Utilização do resíduo gerado na demolição de cubas eletrolíticas de produção de alumínio na fabricação de vidros: (II) Obtenção de vidros opacos.Instituto de PesquisasEnergéticas e Nucleares - IPEN, São Paulo, 2008.

22. VERZIU, M.; FLOREA, M.; SIMON, S.; SIMON, V.; FILIP, P.; PARVULESCU, V. I.; HARDACRE, C.Transesterification of vegetable oils on basic large mesoporous alumina supported alkaline fluorides - Evidences of the nature of the active site and catalytic performances. JournalofCatalysis, v. 263, p. 56-66, 2009.

23. KNOTHE, G. Monitoring a processing transesterification reaction by Fyber-Optic Near Infrared Spectroscopy with correlation to $1 \mathrm{H}$ Nuclear Magnetic Resonance Spectroscopy.JAOCS, v. 77, n. 5, p. 489-493, 2000.

24. SILVA, M. L. P. Síntese e caracterização de peneiras moleculares mesoporosas do tipo MCM-41 e AlMCM-41 a partir de fontes alternativas de sílica e de alumínio. Tese de Doutorado. Programa de Pós-Graduação em Ciências e Engenharia de Materiais. Universidade Federal do Rio Grande do Norte, 2009. 